\title{
A New Test Structure for In-situ Measurements of Interface Recombination During Surface Treatments
}

\author{
S.Daliento, A.Sanseverino, P.Spirito \\ Dept. of Electronic and \\ Telecommunications \\ Via Claudio 21, 80125 Napoli \\ sansever@unina.it
}

\author{
F.Roca \\ R.C.Enea Portici \\ Località Granatello 80055 \\ Portici (Na) \\ roca@portici.enea.it
}

\begin{abstract}
In this paper a new method for to determine the recombination properties of semiconductor interfaces is presented. The recombination velocity is directly estimate by the measurement of a d.c. voltage, that develops on a special fabricate test structure, whose magnitude increases for damaged surfaces and vanishes for passivated surfaces.

Experiments carried out on two silicon samples have shown the unique feature of the method to follow step by step the quality of the surface in a complex process.
\end{abstract}

\section{Introduction}

The surface or interface recombination velocity $\mathrm{S}$ is an important parameter affecting the performances of many semiconductor devices. In spite of its importance, measurement methods usually employed for its evaluation, both optical and electrical, are not fully satisfactory. As it is well known, in fact, optical methods are mainly based on the evaluation of the decay curve of excess minority carriers, this latter is related on the cumulative effect of both bulk and surface recombination. The separation of the two contribution is a complicate task always based on fitting procedures assuming many restrictive hypothesis to be verified [1-2]. Electrical methods often use the dependence of the IV characteristics of semiconductor diodes on the surface recombination and again try to extract $\mathrm{S}$ by fitting experimental data with analytical models [3-4].

In this paper we present an innovative method, based on the operation of a special test device, shown in fig.1, able to directly measure the surface recombination proporties without requiring the knowledge of any critical parameter.

The test device is made by a vertical diode, used to establish a chosen injection level of minority carriers into the epilayer, and by a lateral $\mathrm{n}^{+}$region that is left floating during the operation of the vertical diode and acts as sense terminal. The d.c. voltage manifesting at the sense terminal $\mathrm{V}_{\mathrm{NN}}$ only depends on the recombination properties of the surface between the diffused $\mathrm{n}^{+}$and $\mathrm{p}^{+}$ surface region (exposed surface in Fig.1). In particular the sense voltage tends to 0 if $\mathrm{S}$ is very low (a passivated surface) and increases as $\mathrm{S}$ increases. This latter is an unique feature of the proposed method because the measure of $V_{\mathrm{NN}}$ gives a direct monitoring of the state of the surface without requiring post processing analysis making it suitable as an on line tool for the qualification of surface processes.

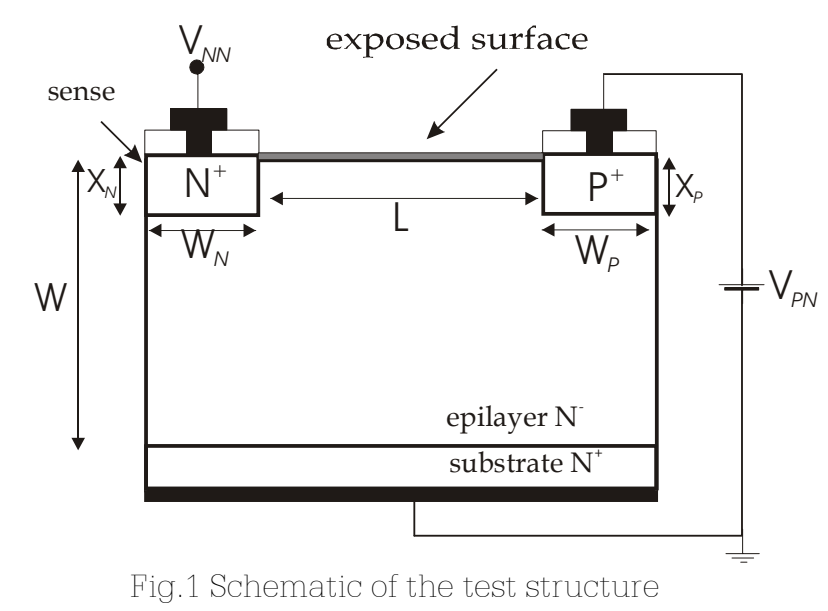

Of utmost importance is the fact that the exposed surface can be conditioned after the fabrication of the test structure so that a number of surface treatments (as RIE, amorphous or oxide deposition etc.) can be analyzed unambiguously by measuring, with the same device, the corresponding recombination velocity after each process.

In this paper the features explained above are experimentally demonstrated. The effects of surface treatments are quantified and related to process conditions. 


\section{Operation and design of the test structure}

The measurement technique we are going to use is a modification of a test device originally developed to characterize, in term of $\mathrm{S}$, the high-low $\mathrm{nn}^{+}$transition between substrate and epitaxial layer.

In our proposal the operation of the test device is adapted to emphasize the effect of recombination on a well controlled surface.

As already stated the measurement method assumes that the vertical diode is forward biased, by the voltage $\mathrm{V}_{\mathrm{PN}}$, thus injecting minority carriers into the epilayer.

If the epilayer thickness $\mathrm{W}$ is less then the minority carriers diffusion length $\mathrm{Lp}$, the concentration of the injected minority carriers $\mathrm{p}(0)$ can be assumed constant in the vertical direction. In the lateral direction the minority carrier concentration decreases because of the vanishing of the holes that recombine on the surface. If the sense region is placed at a distance $\mathrm{L}$ from the $\mathrm{p}^{+}$region less than Lp, then the minority carrier concentration at the epilayer-sense transition $p(L)$ only depends on the surface recombination velocity and on the recombination properties of the sense-epilayer high-low transition. The carrier concentration gradient that appears in the vertical direction corresponds to a d.c. voltage manifesting at the sense terminal.

The recombination velocity associated to the high low transition can be made very low by heavily doping the $\mathrm{n}^{+}$ region with respect to the epilayer. In this case $p(L)$, and hence $\mathrm{V}_{\mathrm{NN}}$, will depend almost entirely on the recombination velocity of the exposed surface.

A one-dimensional analytical approach to the measurement method has been presented in [5], in the following we present a two-dimensional study for the operation of the test structure of Fig.1, showing the direct relation between the surface properties and the sense voltage.

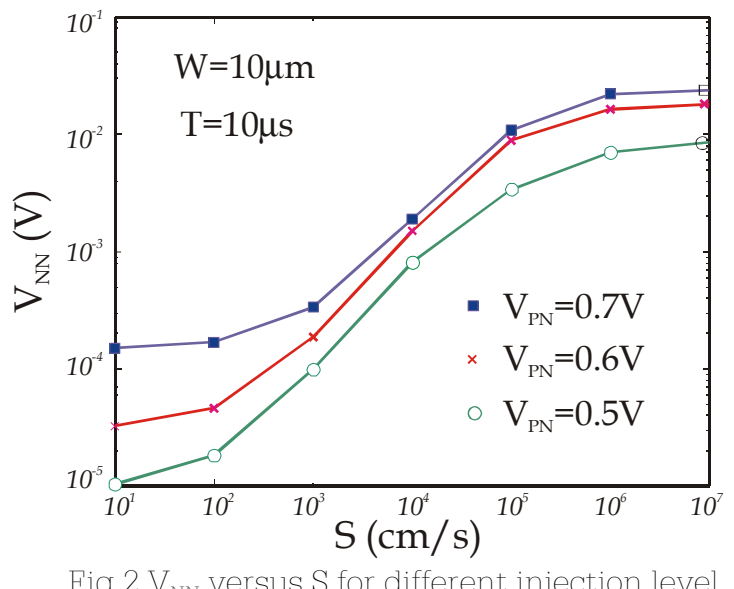

The operation of the structure has been analyzed by setting the value of the surface recombination velocity $S$ on the exposed surface and evaluating the voltage manifesting at the sense terminal when the diode in forward biased.

The results of this analysis are shown in Fig.3 for different values of $\mathrm{V}_{\mathrm{PN}}$. The curves clearly show the sensitivity of the sense voltage $V_{N N}$ respect to surface conditions. The curves saturate for low $\left(<10^{2} \mathrm{~cm} / \mathrm{s}\right)$ and high values of $\mathrm{S}$. The lower value of $\mathrm{V}_{\mathrm{NN}}$ correspond to the recombination velocity related to the $\mathrm{nn}^{+}$transition while for $\mathrm{S}>10^{6} \mathrm{~cm} / \mathrm{s}$ the sense voltage is the same as for $\mathrm{S}$ infinite. The plots of Fig.2 are fully justified by the shape of minority carriers concentration shown in Fig. $3 a /$ b. Fig. 3a shows the carrier distribution when $S$ is set to $10^{2} \mathrm{~cm} / \mathrm{s}$ while Fig. $3 \mathrm{~b}$ hows the carriers distribution for $\mathrm{S}=10^{7} \mathrm{~cm} / \mathrm{s}$.
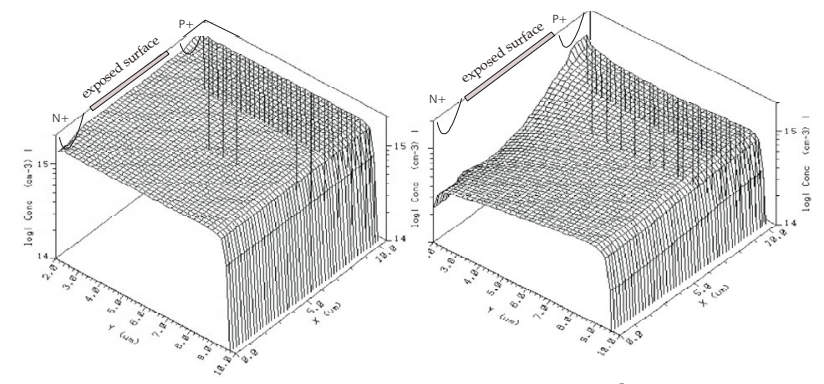

Fig3a-b 3D carrier concentration for a) $\mathrm{S}=10^{2} \mathrm{~cm} / \mathrm{s}$ b) $\mathrm{S}=10^{7} \mathrm{~cm} / \mathrm{s}$

In the first case the hole concentration gradient across the epilayer is very low; in the second case a strong gradient establishes between the epilayer-sense and the epilayer-substrate transitions giving rise to high values of $\mathrm{V}_{\mathrm{NN}}$. The curves obtained above depend on various geometry and physical parameters. In order to design reliable test structures their effects have been studied and simple design rules have been obtained.

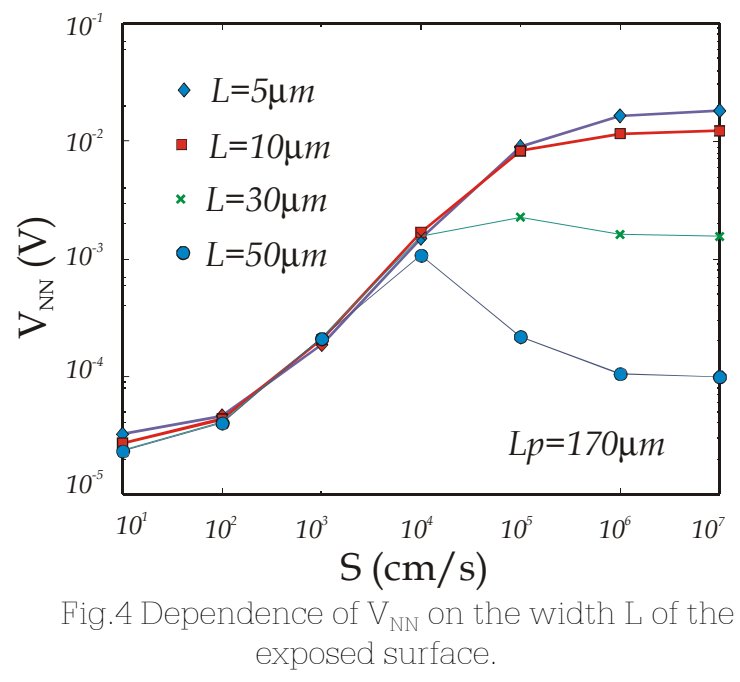

As an example Fig.4 reports the sense voltage $\mathrm{V}_{\mathrm{NN}}$ as a function of $\mathrm{S}$ having fixed the diffusion length $\mathrm{Lp}$, for different distances $\mathrm{L}$ of the sense region; while Fig.5 reports $\mathrm{V}_{\mathrm{NN}}$ for a fixed epilayer thickness $\mathrm{W}$ and different values of $\mathrm{Lp}$. 
The first figure shows that $\mathrm{V}_{\mathrm{NN}}$ is highly sensitive to the value of $\mathrm{S}$ until $\mathrm{L}<\mathrm{Lp} / 10$. The increase of $\mathrm{L}$ makes $\mathrm{V}_{\mathrm{NN}}$ insensitive for higher values of $\mathrm{S}$. When the distance $\mathrm{L}$ becomes comparable with the diffusion length the univocal relationship between $\mathrm{V}_{\mathrm{NN}}$ and $\mathrm{S}$ is completely destroyed.

The second figure shows the constraints that the epitaxial layer thickness has to verify. The figure shows that when the epilayer thickness $\mathrm{W}$ is comparable with the diffusion length $\mathrm{Lp}$ the variation of $\mathrm{V}_{\mathrm{NN}}$ with $\mathrm{S}$ is very low.

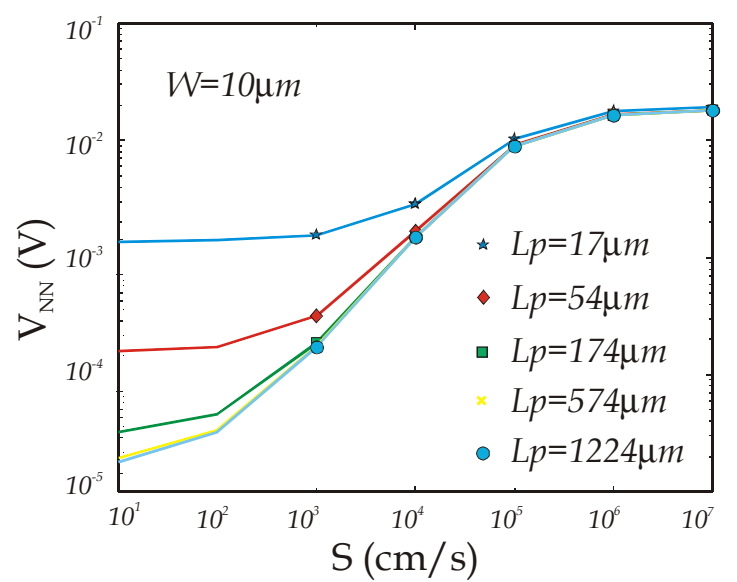

Fig.5 Dependence of $\mathrm{V}_{\mathrm{NN}}$ on the minority carrier diffusion length

The results gained from the above analysis can be summarized in two simple design rules: $\mathrm{L}<\mathrm{Lp} / 10$ and $\mathrm{W}<\mathrm{Lp} / 10$.

\section{Experimental}

The method described above has been used to characterize the fabrication process of an a-Si hetero junction. The effect of each surface treatment has been characterized by measuring the corresponding recombination properties of a specially fabricated test surface embedded in a test device having nominal physical and geometrical parameter shown in Tab. 1. The value of the recombination lifetime has been measured using the differential technique described in [6].

Table 1 Physical and geometrical parameters for the realized structures

\begin{tabular}{|l|l|l|l|}
\hline $\mathrm{L}$ & $15 \mathrm{um}$ & $\tau_{\text {EPI }}$ & $3-10 \mu \mathrm{s}$ \\
\hline $\mathrm{W}_{\mathrm{N}}$ & $15 \mu \mathrm{m}$ & $\mathrm{N}_{\mathrm{SENSE}}$ & $1 \cdot 10^{19} \mathrm{~cm}^{-3}$ \\
\hline $\mathrm{W}_{\mathrm{P}}$ & $15 \mu \mathrm{m}$ & $\mathrm{N}_{\mathrm{P}+}$ & $1 \cdot 10^{19} \mathrm{~cm}^{-3}$ \\
\hline $\mathrm{W}$ & $15 \mu \mathrm{m}$ & $\mathrm{N}_{\mathrm{EPI}}$ & $1 \cdot 10^{15} \mathrm{~cm}^{-3}$ \\
\hline $\mathrm{X}_{\mathrm{N}}$ & $2 \mu \mathrm{m}$ & $\mathrm{X}_{\mathrm{P}}$ & $2 \mu \mathrm{m}$ \\
\hline
\end{tabular}

The top of the realized device has been scanned by a surface profiler. A sketch of the resulting topology is shown in Fig.6. As the surface process we are going to use are masked by aluminum, the effective exposed region is the one between the two aluminum contacts of $\mathrm{p}^{+}$and $\mathrm{n}^{+}$regions. The figure shows that it differs from the nominal exposed surface because of a slight mismatch in the mask alignment. As a consequence the thickness of the covering silicon dioxide is not uniform.

$\mathrm{Al}$

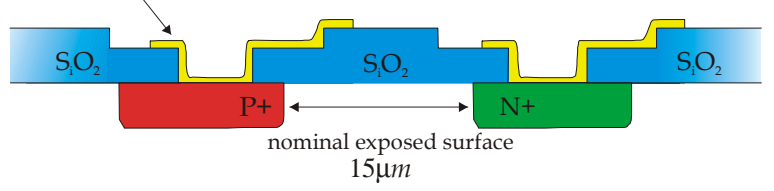

Fig.6 Schematic of the surface profile for the realized structure

The sense voltage has been measured as a function of the diode forward voltage $\mathrm{V}_{\mathrm{PN}}$ prior to perform any treatment. In this case the exposed surface is still covered by the thermal oxide hence the measured values correspond to the recombination velocity at the $\mathrm{Si}_{-} \mathrm{SiO}_{2}$ interface.

After that the thermal oxide has been removed by means of a $45 \mathrm{~min}$. dry etching process performed in a $\mathrm{CF}_{4}$ atmosphere. This process is usually employed to remove the native oxide prior to start with the a-Si deposition. The quality of the surface resulting at this stage is fundamental to ensure good performances of the hetero junction device.

The sense voltage $\mathrm{V}_{\mathrm{NN}}$, measured for three different values of $\mathrm{V}_{\mathrm{PN}}$, is shown in Tab.2 where the results of the subsequent treatments are also reported.

Our measurements show that the recombination velocity has a strong increase after this treatment. This result is not surprising because the silicon surface is no more passivated. The profiler analysis at this stage has shown that only the thinner oxide has been removed. In order to remove also the oxide still present a further 20min. $\mathrm{CF}_{4}$ etch has been performed.

\section{Table2 Experimental results for the first sample}

\begin{tabular}{|c|c|c|c|c|}
\hline \multicolumn{2}{|c|}{ Surface treatments } & $\mathrm{V}_{\mathrm{PN}}=0.6 \mathrm{~V}$ & $\mathrm{~V}_{\mathrm{PN}}=0.7 \mathrm{~V}$ & $\mathrm{~V}_{\mathrm{PN}}=0.8 \mathrm{~V}$ \\
\hline $\mathrm{V}_{\mathrm{NN}}(\mathrm{mV})$ & $\mathrm{S}_{\mathrm{i}} \mathrm{O}_{2}$ & 0.63 & 2.42 & 14.05 \\
\hline $\mathrm{V}_{\mathrm{NN}}(\mathrm{mV})$ & $45^{\prime} \mathrm{CF}_{4}$ & 1.04 & 5.25 & 17.27 \\
\hline $\mathrm{V}_{\mathrm{NN}}(\mathrm{mV})$ & $+20^{\prime} \mathrm{CF}_{4}$ & 1.45 & 6.23 & 17.34 \\
\hline $\mathrm{V}_{\mathrm{NN}}(\mathrm{mV})$ & $+10^{\prime} \mathrm{CF}_{4}$ & 1.57 & 6.47 & 18.07 \\
\hline $\mathrm{V}_{\mathrm{NN}}(\mathrm{mV})$ & $+10^{\prime} \mathrm{CF}_{4}$ & 1.65 & 6.84 & 18.10 \\
\hline $\mathrm{V}_{\mathrm{NN}}(\mathrm{mV})$ & $\mathrm{H}_{2}$ & 3.13 & 12.7 & 22.4 \\
\hline $\mathrm{V}_{\mathrm{NN}}(\mathrm{mV})$ & $\mathrm{O}_{2}$ & 4.71 & 18.8 & 27.8 \\
\hline
\end{tabular}

The voltage $\mathrm{V}_{\mathrm{NN}}$ measured in this case, shown in Tab.2, has an additional increase. The analysis of the surface shows that the thick oxide is still present while the exposed silicon surface has started to etch. The two 
following 10min. etching steps, reported in Tab.2, only caused a further damage of the silicon surface, as highlighted by the slight increment of the sense voltage. Because the etching rate of the silicon surface resulted greater than that of the silicon dioxide, no more etching processes have been performed.

With the aim to further test the sensitivity of our method with respect to surface treatments, two other steps, hydrogenation and oxygenation, have been done. The above treatments are usually employed in p-type silicon to passivate the surfaces. Our results clearly show that, for n-type substrate, a dramatic surface damage occurs probably due to the formation of high recombinating surface states.

A second experiment has been carried out on a different device with the aim to study the silicon/ amorphous-silicon interface. The results are shown in Tab.3.

Table 3 Experimental results for the second sample

\begin{tabular}{|c|c|c|c|c|}
\hline \multicolumn{2}{|c|}{ Surface treatments } & $\mathrm{V}_{\mathrm{PN}}=0.6 \mathrm{~V}$ & $\mathrm{~V}_{\mathrm{PN}}=0.7 \mathrm{~V}$ & $\mathrm{~V}_{\mathrm{PN}}=0.8 \mathrm{~V}$ \\
\hline $\mathrm{V}_{\mathrm{NN}}(\mathrm{mV})$ & $\mathrm{S}_{\mathrm{i}} \mathrm{O}_{2}$ & 1.21 & 9.82 & 46.20 \\
\hline $\mathrm{V}_{\mathrm{NN}}(\mathrm{mV})$ & $30{ }^{\prime} \mathrm{CF}_{4}$ & 7.40 & 37.98 & 93.54 \\
\hline $\mathrm{V}_{\mathrm{NN}}(\mathrm{mV})$ & $\mathrm{a}-\mathrm{S}_{\mathrm{i}}$ & 4.53 & 22.45 & 69.74 \\
\hline
\end{tabular}

Also in this case $\mathrm{V}_{\mathrm{NN}}$ has been first measured with the cover oxide still present and after a $\mathrm{CF}_{4}$ etch. Then a-Si deposition has been performed at $400^{\circ} \mathrm{C}$ in a $\mathrm{SiH}_{4}$ atmosphere. Tab.3 show that the a-Si deposition clearly improves the quality of the interface with respect to the un-passivated one while as it was expected the quality of the surface covered by thermal oxide is still better.

The measured sense voltages can be related to the surface recombination velocities $\mathrm{S}$ by fitting the experimental data with a simulated experiment using only $\mathrm{S}$ as parameter. The result of such procedure, applied to the first device to determine recombination velocity of the $\mathrm{Si}_{-} \mathrm{SiO}_{2}$ interface is shown in Fig. 7 where the result of a sensitivity analysis is also reported.

The circles represent the $\mathrm{V}_{\mathrm{NN}}$ values measured as a function of $\mathrm{V}_{\mathrm{PN}}$, the fitting curve has been obtained by simulating the operation of a device having the same parameters of the real structure (reported in Tab.1) and using $\mathrm{S}=3 \cdot 10^{3} \mathrm{~cm} / \mathrm{s}$. In order to show the reliability of the fitting procedure the curves obtained for different value of $\mathrm{S}$ are also reported. The results show that actual value of $\mathrm{S}$ must be comprise between $1 \cdot 10^{3} \mathrm{~cm} / \mathrm{s}-6 \cdot 10^{3} \mathrm{~cm} / \mathrm{s}$.

The determination of $\mathrm{S}$ has not been repeated for all the experimental data obtained along this work because of the uncertainty regarding the actual extension of the exposed silicon surface. However this fact should not be considered a serious drawback as the emphasis have to be pointed on the capability of the technique to give an immediate picture of the effectiveness of surface processes.

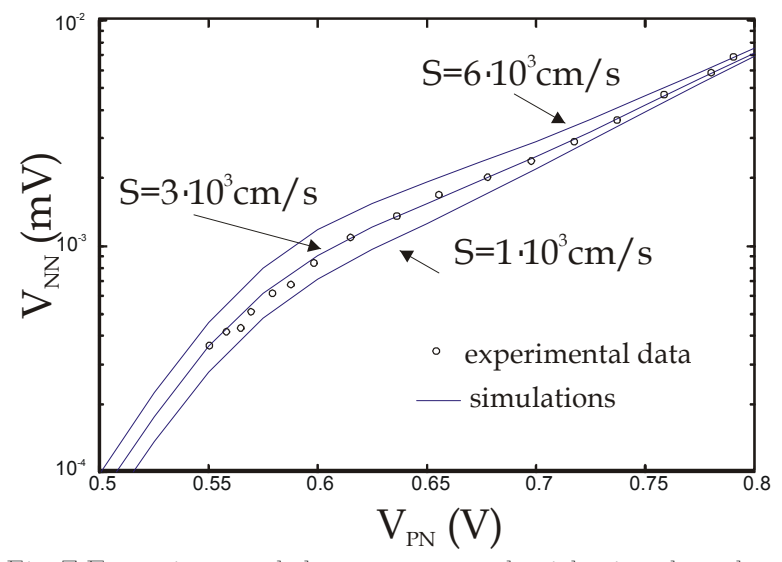

Fig.7 Experimental data compared with simulated fitting curves

The extreme sensitivity of the sense voltage to the variation of the surface condition make the measurement method suitable for on-line monitoring a great variety of technological processes. The results thus obtained could also help to better understand the physic of surface recombination and can be used in process tailoring and design.

\section{Acknowledgments}

We take pleasure in acknowledging the competent technical work of Ivana Nasti in preparing the samples.

\section{References}

[1] A. Cutolo, S. Daliento, A. Sanseverino, G.F. Vitale, L.Zeni," An Optical Technique to Measure the Bulk Lifetime and the Surface Recombination Velocity in Silicon Samples Based on a Laser Diode Probe System, Solid State Electronics, Vol.42, No. 6, pp. 1035-1038, 1998.

[2] M.Spiegel, B.Fisher, S.Keller, E.Bucher, "Separation of Bulk Diffusion Length \& Back Surface Recombination Velocity by Improved IQE-Analysis", $28^{\text {th }}$ IEEE PVSC, Sept.15-22, Anchorage, Alaska, 2000.

[3] A.Morales-Acevedo, G.Santana, "Surface Recombination Velocity in Silicon Substrates Determined from Light Beam Induced Current Measurements, 25 ${ }^{\text {th }}$ PVSC, May13-17, Washington, D.C. pp553-556,1996.

[4] J.C.Duran, G.L.Venier, M.J.L.Tamasi, C.G.Bolzi, J.C.Plà, E.M.Godfrin, "Determination of the Diffusion Length and Surface Recombination Velocity: Two Simple Method" $26^{\text {th }}$ PVSC, Sept.30-Opt.3, Anaheim, CA, pp.195-198,1997.

[5] S.Bellone, A.Caruso, G.Vitale, "Measurement of the Effective Recombination Velocity of Semiconductor High-Low Transition", IEEE TED, Vol. ED-32, No.9, Sept 1985.

[6] S. Daliento, A. Sanseverino, P.M. Sarro, P. Spirito, L. Zeni, " Recombination Centers Identification in Very Thin Silicon Epitaxial Layers via Lifetime Measurements", IEEE Electron. Devices Letters., Vol.17, No.3, pp.148-150, 1996. 